\title{
Fibrodysplasia ossificans Progressive an Early Presentation in the Light of Newer Diagnostic Modalities
}

\author{
Muzamil Mustafa Mugloo* \\ Consaltant Pediatrics \& Neonatology, National Board of Examination, India
}

Submission: January 15, 2017; Published: February 05, 2018

*Corresponding author: Muzamil Mustafa Mugloo, Consaltant Pediatrics \& Neonatology, National Board of Examination, India, Tel:+919596447373; Email: muzamil_mustafa2000@yahoo.com

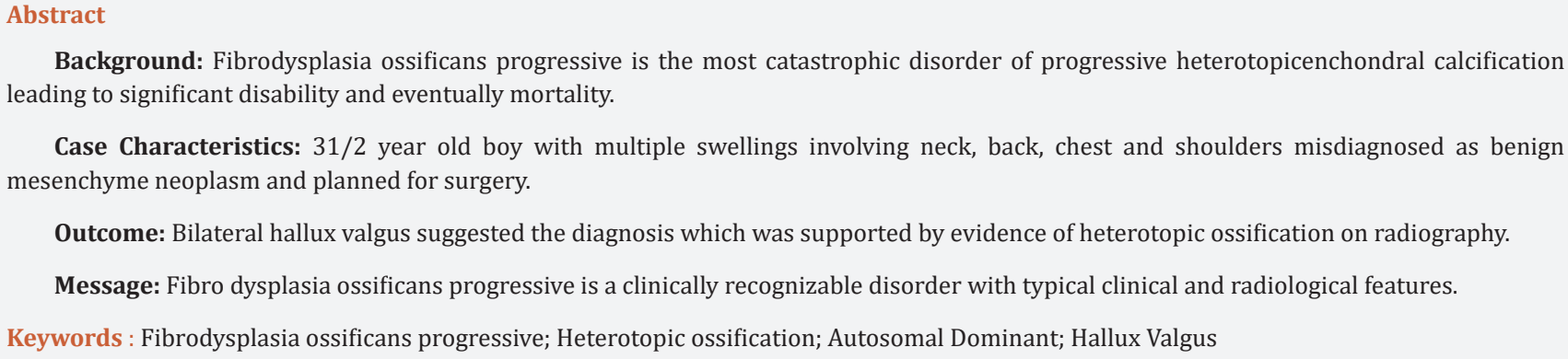

Background: Fibrodysplasia ossificans progressive is the most catastrophic disorder of progressive heterotopicenchondral calcification leading to significant disability and eventually mortality.

Case Characteristics: 31/2 year old boy with multiple swellings involving neck, back, chest and shoulders misdiagnosed as benign mesenchyme neoplasm and planned for surgery.

Outcome: Bilateral hallux valgus suggested the diagnosis which was supported by evidence of heterotopic ossification on radiography.

Message: Fibro dysplasia ossificans progressive is a clinically recognizable disorder with typical clinical and radiological features.

Keywords : Fibrodysplasia ossificans progressive; Heterotopic ossification; Autosomal Dominant; Hallux Valgus

\section{Introduction}

Fibrodysplasia ossificans progressiva (FOP) or myositis ossificans progressiva also known as Munchmeyer disease is a rare disabling genetic condition characterized by congenital malformation of great toes and progressive heterotopicen chondralcalcification (HEO) in a specific anatomic patterns. The misdiagnosis of FOP approaches 90 percent of affected individuals worldwide [1]. Children often undergo unnecessary and harmful diagnostic biopsies that exacerbate the progression of the condition [2]. Thus establishing the diagnosis of FOP correctly as soon as possible based on history, clinical findings and imaging is pivotal. Here, we report an intriguing case of a three and a half year old boy with FOP with early extensive involvement misdiagnosed earlier in spite of the early occurrence of the typical presentation of FOP for more than two years.

\section{Case Report}

This 31/2 year old boy presented with multiple painful swellings on back and chest with reduced range of movements at multiple joints predominantly at axial skeleton. He was fourth child born of a non- consanguineous marriage of a 34 yearold mother by normal vaginal delivery without any adverse perinatal event with a birth weight of 2860 grams. There was no family history of similar disease and other siblings were normal. Growth and development was consistent with child's age.
Two years back swellings had been initially noticed by parents on the occiput. Subsequently similar swellings were noticed involving neck, back, chest and shoulders. There was history of pain in the swellings at the time of appearance lasting for days to weeks. In the previous hospital, FNAC was performed on the periscapular mass despite what might lead to catastrophic disability. Child was misdiagnosed as benign mesenchyme neoplasmand planned for surgery to relieve mobility at axial skeletal joints and hence referred to our hospital.

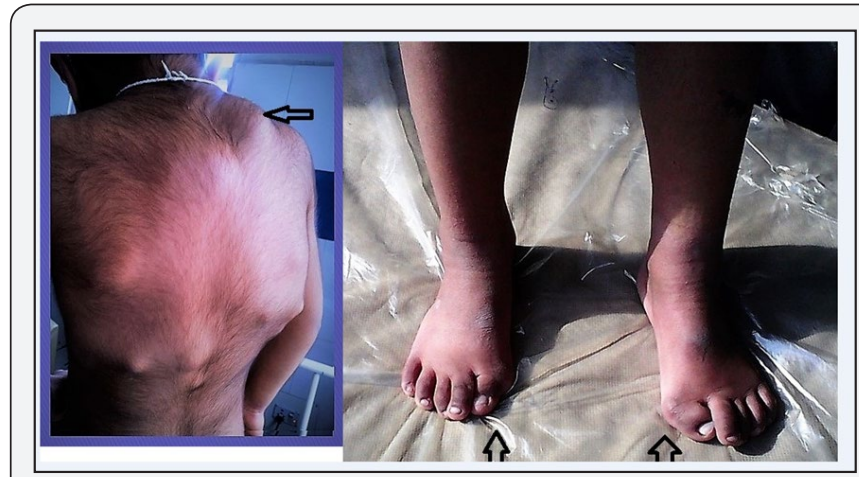

Figure 1.

At admission, child had swellings involving entire back, shoulders and chest which were firm, non- tender, without 
redness or any signs of inflammation over the skin (Figure 1) Bilateral hallux valgus was noticed which is a hallmark of this disease (Figure 1). Skeletal radiographs show edextensive heterotopic ossifications in rib cage, spine and occipital region (Figure 2). Ultrasonography of swellings showed solid hypoechoic masses adhered to the rib cage and spine. Rest of the systemic examination was unremarkable. Other hematological and biochemical investigations revealed $\mathrm{Hb}-12.7$, TLC- 9,600/ cu mm (P44, L45, E09, M2), serum Calcium- 9.2 mg/dl; serum Phosphorus-5.4 mg/dl; CPK-57 IU/L, SGPT -28 IU/ L; and alkaline phosphatase-40 KAU. ECG was normal.

The radiological skeletal survey revealed extensive heterotopic ossification in neck, thoracic walls, back, upper limbs and hips with bone deformities (Figure 2). CT thorax showed multiple plaque-like calcifications involving the pectoralis major and para-spinal muscles (Figure 3). Diagnosis of FOP was strongly considered. Blood samples of both the parents and child were collected for sequencing the activing receptor IA (ACVR1) gene. A heterozygous mutation(617 G>A; q.R206H), which is the most common mutation reported to be associated with FOP, was detected in the child confirming the diagnosis As there were no acute flare-ups, no NSAID's or steroids were given. The child was given graded physiotherapy and parents were explained the nature of ailment with precautions to prevent trauma (particularly iatrogenic injury from intra-muscular injections, biopsies, and surgery) and trivial injuries inflicted during playful activities.

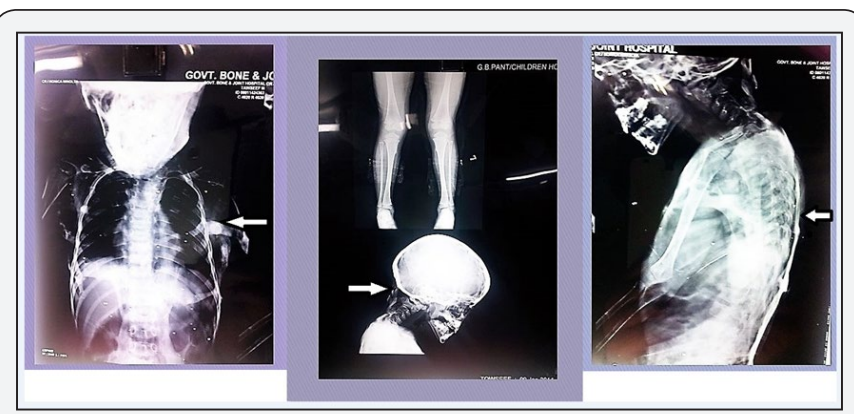

Figure 2.

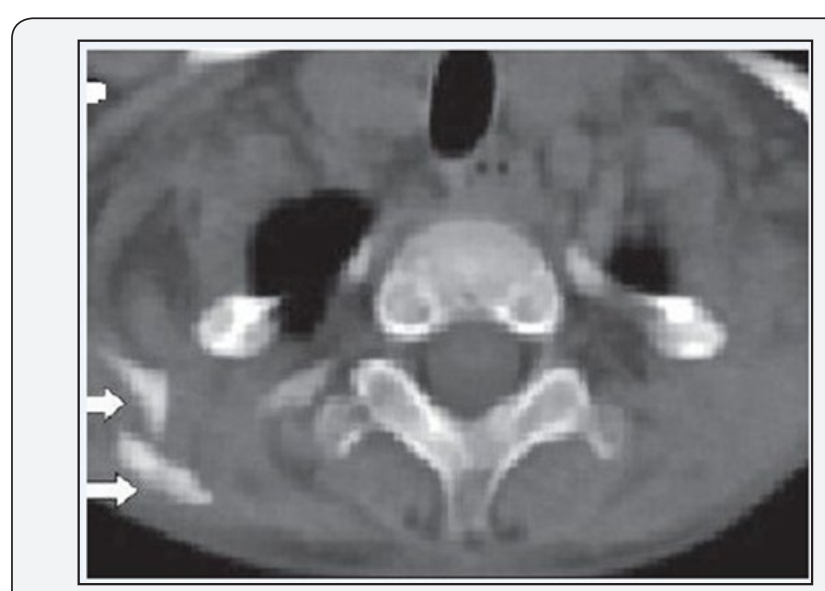

Figure 3.

\section{Discussion}

Prevalence is approximately $1 / 2.000 .000$ and over 700 cases have been reported in the world literature to date. Inherited in auto somal dominant manner while most cases arise from spontaneous new mutations [3]. Individuals with FOP appear normal at birth except for characteristic malformation of great toes. Children with FOP develop episodic painful soft tissue swellings (or flare-ups) in response to minor trauma such as trivial fall, intramuscular immunizations, blunt muscle trauma from bumps, bruises or influenza like viral illnesses [4].

While some flare-ups regress spontaneously, most transform soft connective tissues including aponeurosis, fascia, ligaments, tendons and skeletal muscle into mature heterotopic bone. Bone formation is episodic but immobility is cumulative. Most of the patients are confined to a wheel chair by the third decade requiring lifelong assistance for performing activities of daily living. In addition, ossification of thoracic soft tissue causes scoliosis and restrictive pulmonary disease predisposing to pneumonia and right sided heart failure and consequently death in the third or fourth decade prevalently [5].

The mean age of symptom onset is between 2 and 5 years and the mean age at onset of ossification has been reported as 5 years [6]. In our case, the onset of symptoms with the typical anatomic pattern occurred at one year of age. The ossification process can intensify in the presence of trauma, as occurred in our case where the child had heterotopic ossification early at the age of $31 / 2$ years.

FOP should be diagnosed as early as possible based on history, clinical and imaging findings. The guide of diagnosis is bilateral anomaly of the great toes present from birth, reported almost in $100 \%$ of the patients [7].

\section{Roentgenogram}

Demonstrates minor osseous dimorphism such as hallux valgus, phalangeal shortening, metacarpal and metatarsal shortening, short widened femoral neck, fusion of the spine and increased exostosis. When the ectopic ossification occurs, bony bridges running from the bones to the muscles spreading along the fascial planes are seen.

\section{Ultrasonography}

Early lesions may show sonolucent soft tissue mass and then when ossification occurs, echogenic and shadowing mass is detected.

\section{CT scan}

CT demonstrates fascia plane edema and swelling and mesenchymal mass like lesion in the muscle that moderately enhances with IV contrast. In late disease after ossification and calcification

\section{MRI}

MRI finding of a pre-osseous lesion is sufficient for accurate diagnosis of FOP in early stage when ectopic ossification is not 
present. In T1 weighted images, a mass effect with displacement of fascia plane and in T2 weighted images, a homogeneous soft tissue mass markedly enhanced with contrast is seen. Late MRI shows low T1 and T2 signal intensity associated with fibrous or calcified tissue.

\section{Genetic Diagnosis}

A definitive genetic testing of FOP is now available and can confirm diagnosis prior to appearance of heterotopic ossification. Majority of the affected cases reported till date have been found to have identical heterozygous mutation (617G --> A; R206H) in the glycine-serine (GS) activation domain of ACVR1, a BMP type I receptor [8].

FOP has many differential diagnoses. Patients may be misdiagnosed with malignant tumors especially sarcoma, rhabdomyosarcoma, aggressive fibromatosis, post traumatic myositis, lymphadenopathy, TB, scleroderma, dermatomyositis of childhood, RA and nodular fasciitis and Klippel-Feil syndrome.

In summary, in review of case series, case reports, articles of diagnostic errors, and our case, we conclude that FOP is often misdiagnosed and the correct diagnosis happens very late. Early diagnosis prevents catastrophic harmful diagnostic and treatment procedures. The severe disability produced by this disease merits early recognition so that good general care and avoidance of trauma (particularly iatrogenic trauma from intramuscular injections, biopsies, and surgery) may be emphasized.

For early correct diagnosis we propose: Clinician's should be aware of the early diagnostic signs of FOP which are congenital malformation of great toes and episodic soft tissue swelling even before the appearance of heterotopic ossification. This awareness should prompt genetic consultation and testing (if appropriate) and the institution of assiduous precautions to prevent iatrogenic trauma and harm.

\section{References}

1. Kitterman Joseph A, Sharon Kantanie, David M Rocke, Frederick S Kaplan (2005) Iatrogenic harm caused by diagnostic errors in fibrodysplasia ossificans progressiva. Pediatrics 116 (5): 654-661.

2. Zaghloul KA, Heuer GG, Guttenberg MD, Shore EM, Kaplan FS, et al. (2008) Lumbar puncture and surgical intervention in a child with undiagnosed fibrodysplasia ossificans progressiva. J Neurosurg Pediatr 1(1): 91-94.

3. Kaplan FS, McCluskey W, Hahn G, Tabas JA, Muenke M, et al. (1993) Genetic transmission of fibrodysplasia ossificans progressiva. Report of a family. J Bone Joint Surg Am 75(8): 1214-1220.

4. Lanchoney Thomas F, Randolph B Cohen, David M Rocke, Michael A Zasloff, Kaplan FS (1995) Permanent heterotopic ossification at the injection site after diphtheria-tetanus-pertussis immunizations in children who have fibrodysplasia ossificans progressiva. J Pediatr 126(5): 762-764.

5. Kaplan FS, Zasloff MA, Kitterman JA, Shore EM, Hong CC, et al. (2010) Early mortality and cardio respiratory failure in patients with fibrodysplasia ossificans progressiva. J Bone Joint Surg Am 92(3): 686691.

6. Cohen RB, Hahn GV, Tabas JA, Peeper J, Levitz CL, et al. (1993) The natural history of heterotopic ossification in patients who have fibrodysplasia ossificans progressiva. A study of forty-four patients. ] Bone Joint Surg Am 75(20): 215-219.

7. Kaplan FS, Xu M, Glaser DL, Collins F, Connor M, et al. (2008) Early diagnosis of fibrodysplasia ossificans progressiva. Pediatrics 121(50): $1295-1300$

8. Shore EM, Xu M, Feldman GJ, Fenstermacher DA, Cho TJ, et al. (2006) A recurrent mutation in the BMP type I receptor ACVR1 causes inherited and sporadic fibrodysplasia ossificans progressiva. Nat Genet 38 (5): 525-527.

\section{Your next submission with Juniper Publishers} will reach you the below assets

- Quality Editorial service

- Swift Peer Review

- Reprints availability

- E-prints Service

- Manuscript Podcast for convenient understanding

- Global attainment for your research

- Manuscript accessibility in different formats

( Pdf, E-pub, Full Text, Audio)

- Unceasing customer service

Track the below URL for one-step submission https://juniperpublishers.com/online-submission.php 